\title{
PENGARUH PERCEIVED QUALITY, BRAND AWARENESS, BRAND IMAGE TERHADAP BRAND LOYALTY DALAM INDUSTRI PERBANKAN SYARIAH
}

\author{
NUNO SUTRISNO \\ SATRIA NURRAHMAT \\ Sekolah Tinggi Ilmu Ekonomi Trisakti, Jl. Kyai Tapa No. 20, Jakarta, Indonesia \\ nuno@stietrisakti.ac.id, satrianurrahmat7@gmail.com
}

\begin{abstract}
The purpose of this study was to determine the effect of Perceived Quality, Brand Awareness, Brand Image on Brand Loyalty at Bank Muamalat in DKI Jakarta. The research method used in this research is through a survey. The data were analyzed quantitatively and used a causal research design. The sampling method used in this study is to use Non-Probability Sampling with purposive sampling technique. All sample data obtained by distributing questionnaires totaled 113 respondents and will be processed using SPSS 23 software. The data analysis technique used in this research is multiple linear regression. The results of this study indicate that Perceived Quality, Brand Awareness and Brand Image have an influence on Brand Equity. This research is expected to provide input or suggestions to Islamic Banking, especially Bank Muamalat which is the object of this research, in order to increase its market share in the Islamic banking industry in Indonesia.
\end{abstract}

Keywords: Perceived quality, brand awareness, brand image, brand loyalty

Abstrak: Tujuan penelitian ini adalah untuk mengetahui pengaruh Perceived Quality, Brand Awareness, Brand Image terhadap Brand Loyalty pada Bank Muamalat di DKI Jakarta. Metode penelitian yang diguanakan dalam penelitian ini adalah melalui survey. Analisis data dilakukan secara kuantitatif dan menggunakan rancangan penelitian bersifat kausalitas. Metode pengambilan sampel yang diguankan dalam penelitian ini adalah dengan menggunakan Non-Probability Sampling dengan teknik Purposive Sampling. Seluruh data sampel yang diperoleh melalui penyebaran questioner berjumlah 113 responden dan akan diolah dengan mengguanakan software SPSS 23. Teknik analisis data yang digunakan dalam penelitian ini adalah regresi linear berganda. Hasil dari penelitian ini menunjukan bahwa Perceived Quality, Brand Awareness dan Brand Image memiliki pengaruh terhadap Brand Equity. Penelitian ini diharapkan dapat memberikan masukan atau saran kepada Perbankan Syariah terutama Bank Muamalat yang merupakan objek dalam penelitian ini, agar mampu meningkatkan pangsa pasarnya pada indusrtri perbankan di Indonesia.

Kata Kunci: Perceived quality, brand awareness, brand image, brand loyalty

\section{PENDAHULUAN}

Keuangan syariah di Indonesia telah berkembang lebih dari dua dekade sejak beroperasinya bank syariah pertama di Indonesia. Perkembangan keuangan syariah telah membuahkan berbagai prestasi, dari makin banyaknya produk dan layanan, hingga berkembangnya infrastruktur yang mendukung keuangan syariah. Bahkan di pasar global, Indonesia termasuk dalam sepuluh besar negara yang memiliki indeks keuangan syariah terbesar di dunia. 
Perkembangan Bank Syariah di Indonesia kini telah menjadi tolak ukur keberhasilan eksistensi ekonomi syariah. Krisis moneter yang terjadi pada tahun 1998 telah menenggelamkan bank-bank konvensional dan banyak di likuidasi karena kegagalan sistem bunganya, sementara perbankan yang menerapkan sistem syariah dapat tetap eksis dan mampu bertahan.

Tidak hanya itu, di tengah-tengah krisis keuangan global yang melanda dunia pada ujung akhir tahun 2008, lembaga keuangan syariah kembali membuktikan daya tahannya dari terpaan krisis. Lembaga-lembaga keuangan syariah tetap stabil dan memberikan keuntungan, kenyamanan serta keamanan bagi para pemegang sahamnya, pemegang surat berharga, peminjam dan para penyimpan dana di bank-bank syariah.

Menurut Otoritas Jasa Keuangan (OJK), sejauh ini, kinerja perbankan syariah masih terpantau positif. Perbankan syariah hingga bulan Maret 2019 terus menunjukkan perkembangan positif dengan Aset, Pembiayaan Yang Disalurkan (PYD), dan Dana
Pihak Ketiga (DPK) yang terus bertumbuh, dimana pertumbuhan Aset sebesar 12,04 persen, Pembiayaan yang Disalurkan (PYD) sebesar 14,15 persen, dan Dana Pihak Ketiga sebesar 10,28 persen. Berdasarkan data tersebut menunjukkan bahwa perbankan syariah benar-benar tahan dan kebal krisis dan mampu tumbuh dengan signifikan. Dengan pertumbuhan Aset, Pembiayaan dan Dana pihak ketiga dari perbankan syariah ini menujukan penerimaan yang baik dari masyarakat Indonesia yang merupakan Negara dengan jumlah penduduk muslim terbesar di dunia. Fenomana ini tentunya akan memacu semua Bank Syariah yang ada di Indonesai untuk bersaing memperebutkan pangsa pasar yang sangat besar tersebut. Berdasarkan data Otoritas Jasa Keuangan terdapat 14 Bank Umum Syariah di Indonesia sampai saat ini, dari jumlah tesebut jika dilihat dari data Top Brand Index (TBI), terdapat beberapa bank umum syariah yang bersaing dalam lima besar berdasarkan Top Brand Award 5 tahun terakhir, yaitu periode tahun 2014 samapai dengan 2018, yang secara rinci ditunjukan tabel beriktu:

Tabel 1 Top Brand Index Award2014-2018

\begin{tabular}{lccccc}
\hline \multicolumn{1}{c}{ Bank } & $\mathbf{2 0 1 4}$ & $\mathbf{2 0 1 5}$ & $\mathbf{2 0 1 6}$ & $\mathbf{2 0 1 7}$ & $\mathbf{2 0 1 8}$ \\
\hline $\begin{array}{l}\text { Bank Syariah } \\
\text { Mandiri }\end{array}$ & & & & & \\
& $32,9 \%$ & $27,4 \%$ & $31,5 \%$ & $26,1 \%$ & $27,5 \%$ \\
BRI Syariah & $21,6 \%$ & $28,5 \%$ & $26,4 \%$ & $22,9 \%$ & $27,5 \%$ \\
BNI Syariah & $13,9 \%$ & $13,5 \%$ & $15,9 \%$ & $15,2 \%$ & $27,0 \%$ \\
BCA Syariah & $3,2 \%$ & $9,5 \%$ & $3,6 \%$ & $3,8 \%$ & $6,5 \%$ \\
Bank & & & & & \\
Muamalat & $15,8 \%$ & $10,8 \%$ & $10,1 \%$ & $13,3 \%$ & $4,2 \%$ \\
\hline
\end{tabular}

Sumber: Tob Brand Index Award (di akses pada September 2018)

Berdasarkan data tabel 1 diatas, dapat dilihat bahwa secara rata-rata dalam lima tahun terakhir Bank Mandiri Syariah menempati posisi pertama dalam TBI, hal ini menggambarkan bahwa Bank Mandiri Syariah memiliki pangsa pasar terbesar pada industri perbankan syariah tersebut. Kemudian disusul oleh Bank BRI
Syariah, BNI Syariah dan BCA Syariah. Lebih lanjut data pada tabel 1 tersebut menujukan bahwa secara presentasi bank-bank tersebut bersaing cukup ketat untuk menjadi yang pertama dalam TBI dan dengan nilai indeks yang secara umum mengalami peningkatan. Kondisi ini berbanding terbalik dengan nilai 
indeks dari Bank Muamalat, dimana dalam data tersebut terlihat bahwa secara indeks nilai TBI Bank Muamalat dari tahun 2014 sampai 2018 terus mengalami penurunan, dimana secara keseluruhan nilai TBI yang dapat menggambarkan posisisi pangsa pasar dari Bank Muamalat mengalami penurunan dari 15,8\% pada tahun 2014 menjadi 4,2\% pada tahun 2018. Hal ini menyebabkan posisi Bank Muamalat turun dari posisis ke tiga pada tahun 2104 menjadi posisi terbawah dari lima besar perbankan syariah yang masuk kedalam Top Brang Index Award pada tahun 2108. Kondisi ini tentunya harus menjadi perhatian bagi Bank Muamalat untuk dapat menerapkan sebuah cara atau strategi agar dapat meningkatkan kembali posisi TBI atau posisi pangsa pasarnya. Hal ini seharusnya menjadi hal yang bukan tidak mungkin, karena sebetulnya jika dilihat dari sejarah berdiriannya, Bank Muamalat sendiri adalah bank umum pertama di Indonesia yang menerapkan prinsip Syariah Islam dalam menjalankan operasionalnya yang resmi beroperasi pada tahun 1992 dan menjadikannya maskot bank syariah di Indonesia. Dengan statusnya sebagai Bank Umum Syariah pertama di Indonesia, Bank Muamalat menjadi pilot project dan trademark kebangkitan serta implementasi secara besar-besaran pemikiran hukum ekonomi Islam di Indonesia pada saat itu dan moment berdirinya sangat ditunggu-tunggu oleh masyarakat Indonesia.

Salah satu strategi yang dapat dilakukan oleh perbankan syariah terutama Bank Muamalat yang menjadi objek dalam penelitian ini agar dapat meningkatkan pangsa pasar dalam industri perbankan syariah, adalah dengan mencipatakan Brand Loyalty kepada setiap nasabahnya.

Brand Loyalty merupakan ukuran seberapa sering konsumen membeli secara berulang produk dari suatu merek di masa yang akan datang (Schiffman dan Wisenblit; 2015:168). Kosunumen yang loyal akan ditandai dengan melakukan pembelian berulang dimasa yang akan datang dan tidak segan untuk membagikan informasi positif mengenai merek kepada orang lain serta mengajak orang lain untuk menggunakan atau mengkonsumsi merek yang digunakan atau dikonsumsinya. Dengan kondisi konsumen yang melakukan pembelian kembali, menyebarkan informasi positif (positif word of mouth (WOM) dan mengajak orang lain untuk mengkonsumsi merek yang digunakannya, tentu saja akan berdampak pada peningkatan penjualan merek tersebut, dan secara jangka panjang akan berpengaruh pada peningkatan pangsa pasar dari merek yang bersangkutan. Hal ini sesuai dengan penelitian yang dilakukan oleh Gounaris dan Stathakopoulos (2004) yang mengyatakan bahwa loyalitas merek dapat meningkatkan market share dari merek yang bersangkutan. Hal senada diungkapkan dalam penelitian yang dilakukan oleh Jansen dan hansen (2016) yang menyatakan bahwa brand loyalty meningkatkan pangsa pasar secara eksponensial.

Berdasarkan uraian latar belakang diatas, maka penting bagi perbankann syariah yang memiliki permasalahan dari sisi pangsa pasar, terutama Bank Muamalat yang menjadi objek dalam penelitian ini, untuk dapat meningkatkan Brand Loyalty dari para nasabahnya, karena akan berdampak pada peningkatan pangsa pasar dari produk atau layanan yang dijualnya.

Berdasarkan penelitian yang dilakukan Altaf et al (2017) mengungkapkan bahwa Perceived Quality, Brand Awareness, dan Brand Image mempunyai pengaruh dan dapat menciptakan Brand Loyalty.

\section{Perceived Quality}

Perceived Quality merupakan semua penilaian dari semua aspek dan pemikiran dalam benak konsumen terhadap pelayanan yang diberikan oleh perusahaan (Zeithaml, 1988). Menjadii penting bagi setiap perbankan untuk dapat memberikan pelayanan yang baik kepada para nasabahnya, karena jika para nasabah menilai baik layanan yang diberikan oleh perusahaan atau brand, maka pelanggan 
akan menunjukan loyalitasnya. Berdasarkan hal tersebut, maka setiap perbankan perlu untuk terus dapat meningkatkan Perceived Quality dari para nasabahnya, karena semakin baik Perceived Quality dari para nasabah kepada perusahaan atau brand maka akan menciptkan dan meningkatkan Brand Loyalty kepada perusahaan atau brand tersebut (Dinnie et al, 2010) (Keller dan Lehmann, 2006). Berdasarkan urain dan teori diatas, maka dapat disusun Hipotesis yang pertama sebagai berikut:

$\mathrm{H}_{1}$ Terdapat pengaruh Perceived Quality terhadap Brand Loyalty

\section{Brand Awareness}

Brand Awareness mengarah pada kemampuan konsumen mengingat, mengenali brand, dan dapat menghubungkannya kepada logo, nama brand, dan hal-hal lainnya mengenai brand tersebut (Altaf et al .,2017). Menjadi penting bagi perusahaan agar konsumen dapat mengenali dan mengingat merek perusahaan dengan mudah. Perusahaan harus dapat mengkomunikasikan produk atau brand perusahaan dengan baik kepada target market yang paling sesuai dengan produk atau merek yang akan dijual.

Semakin baik konsumen mengenal atau sadar akan sebuah produk atau brand baik secara logo, nama atau hal lainnya, tentusaja konsumen akan jauh lebih memilih atau membeli kembali produk tersbut dibandingkan produk atau brand yang belum atau tidak konsuemn kenal. Hal ini sangant dipahami karena ketika konsmen akan mebeli kembali sebuah produk sangat berhubungan langsung dengan informasi yang ada dibenak konsumen. Semakin konsumen mengenali (aware) maka produk atau brand tersebut memiliki kesempatan yang tinggi untuk dibeli kembali oleh konsumen atau loyal (Moisescu, 2009). Berdasarkan uraian dan teori diatas, maka dapat disusun Hipotesisi ke dua sebagai berikut:

$\mathrm{H}_{2}$ Terdapat pengaruh Brand Awareness terhadap Brand Loyalty

\section{Brand Image}

Brand Image merupakan kumpulan dari kesan yang diterima atau didapat oleh konsumen dari berbagai sumber atau keyakinan konsumen tentang suatu brand (Keller, 1993) dan akan membentuk persepsi merek yang tercermin dari ikatan merek yang diingat dalam memori konsumen (Keegan dan Green, 2015:319). Oleh karenanya penting bagi perbankan atau perusahaan untuk dapat menanamkan brand Image dari sebuah produk atau layanan dalam benak atau memori konsumen, hal ini dikarenakan ketika seorang konsumen membeli sebuah produk atau layanan dengan brand tertentu, cendrung diarahkan oleh kesan, persepsi dan ingatan mereka akan sebuah brand didalam benak atau memori mereka.

Kesan yang didapatkan, persepsi dan ingatan konsumen tentang suatu brand dapat dijadikan pertimbangan oleh konsumen dalam melakukan pembelian. Jika kesan, persepsi dan ingatan konsumen mengenai produk atau brand baik, maka akan mendorong kosumen untuk lebih memilih dan terus menggunakan atau loyal pada produk atau brand tersebut, dengan kata lain Semakin kuat brand image dalam benak atau pikiran konsumen maka akan membentuk dan meningkatkan Brand Loyalty konsumen atau nasabah akan produk atau brand yang bersangkutan. Hal ini senada dengan penelitian yang dilakukan oleh Altaf et al (2017) yang menyatakan Persepsi suatu merek yang ada di benak konsumen dapat berbentuk identitas merek dan kesadaran merek yang selanjutnya konsumen dapat membedakan brand-brand yang ada dan dapat membentuk loyalitas brand di masa depan. Berdasarkan uraian dan teori diatas, maka dapat disusun Hipotesisi ke tiga sebagai berikut::

$\mathrm{H}_{3}$ : Terdapat pengaruh Brand Image terhadap Brand Loyal

Berdasarkan uraian kerangka teoritis dan pengembangan hipotesis diatas, maka 
dapat digambarkan bentuk pengaruh Perceived Quality, Brand Awareness, Brand Image terhadap Brand Loyalty dalam sebuah kerangka konseptual sebagai beriktu:

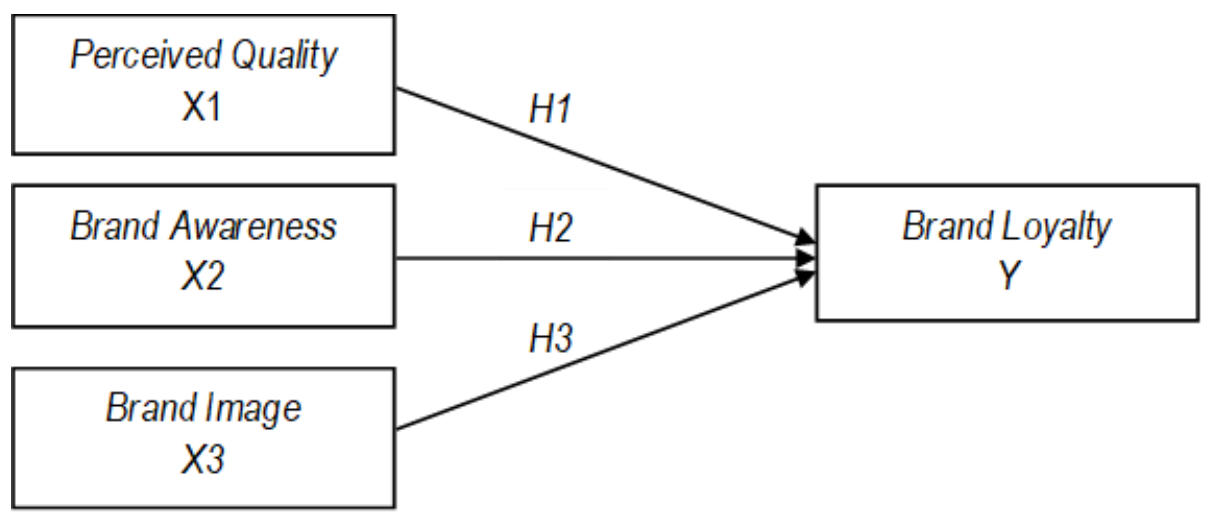

Gambar 1 Kerangka Konseptual

\section{METODE PENELITIAN}

Metode penelitian yang diguanakan dalam penelitian ini adalah melalui survey. Analisis data dilakukan secara kuantitatif dan menggunakan rancangan penelitian bersifat kausalitas. Hal ini bertujuan untuk mengetahui pengaruh antara Perceived Quality, Brand Awareness, Brand Image terhadap Brand Loyalty pada nasabah Bank Muamalat di DKI Jakarta. Teknik analisis data yang digunakan dalam penelitian ini adalah regresi linear berganda. Metode pengambilan sampel yang diguankan dalam penelitian ini adalah dengan menggunakan Non-Probability Sampling dengan teknik Purposive Sampling. Pengambilan data primer dilakukan dengan cara membagikan questioner kepada nasabah Bank Muamalat di wilayah DKI Jakarta. Seluruh data sampel yang diperoleh melalui penyebaran questioner berjumlah 113 responden dan akan diolah dengan mengguanakan software SPSS 23 (Statistical Package for Social Science).

\section{HASIL DAN PEMBAHASAN}

Uji Validitas digunakan untuk mengukur sah atau valid tidaknya suatu kuesioner (Ghozali, 2018:51). Item pertanyaan dalam kuesioner dinyatakan valid jika nilai $r$ tabel dari seluruh pertanyaan lebih besar jika dibandingkan dengan nilai $r$ hitung. Sedangkan pengujian reliabilitas digunakan untuk mengetahui apakah butir-butir pertanyaan yang ada pada kuesioner dapat menghasilkan jawaban yang konsisten atau stabil dari waktu ke waktu (Sekaran dan Bougie, 2016:137). Item pertanyaan dalam kuesioner dinyatakan reliabel jika keseluruhan item pertanyaan memiliki nilai cronbach's alpha > 0,60 (Sekaran dan Bougie, 2016:290). Berdasarkan tabel diatas dapat terlihat bahwa keseluruhan item pertanyaan dalan kuesioner memiliiki nilai $r$ hitung $>r$ tabel, sehingga dapat disimpulkan bahwa seluruh item pertanyaan yang dibuat alam kuesioner dinyatakan valid. Begitu juga untuk pengujian reliabilitas, tabel diatas menujukan bahwa keseluruhan item pertanyaan memiliiki nilai cronbach's alpha $>0,60$, sehingga dapat disimpulkan bahwa seluruh item pertanyaan yang dibuat alam kuesioner dinyatakan reliabel. 
Tabel 2 Hasil Uji Validitas dan Reliabilitas

\begin{tabular}{|c|c|c|c|c|c|c|}
\hline Variabel & $\begin{array}{c}\text { Item } \\
\text { pertanyaan }\end{array}$ & $r$ hitung & $\begin{array}{c}r \text { tabel } \\
(d f=111)\end{array}$ & Keterangan & $\begin{array}{c}\text { Cronbach } \\
\text { alpha }\end{array}$ & Keterangan \\
\hline Perceived & $P Q 1$ & 0,778 & 0,1848 & Valid & \multirow{4}{*}{0,879} & \multirow{4}{*}{ Reliabel } \\
\hline \multirow[t]{3}{*}{ Quality (X1) } & $P Q 2$ & 0,891 & 0,1848 & Valid & & \\
\hline & $P Q 3$ & 0,909 & 0,1848 & Valid & & \\
\hline & $P Q 4$ & 0,865 & 0,1848 & Valid & & \\
\hline Brand & BA 1 & 0,866 & 0,1848 & Valid & \multirow{4}{*}{0,898} & \multirow{4}{*}{ Reliabel } \\
\hline \multirow{3}{*}{$\begin{array}{c}\text { Awareness } \\
\text { (X2) }\end{array}$} & BA 2 & 0,920 & 0,1848 & Valid & & \\
\hline & BA 3 & 0,902 & 0,1848 & Valid & & \\
\hline & BA 4 & 0,813 & 0,1848 & Valid & & \\
\hline \multirow{4}{*}{$\begin{array}{l}\text { Brand Image } \\
\text { (X3) }\end{array}$} & $\mathrm{BI} 1$ & 0,877 & 0,1848 & Valid & \multirow{4}{*}{0,868} & \multirow{4}{*}{ Reliabel } \\
\hline & $\mathrm{BI} 2$ & 0,859 & 0,1848 & Valid & & \\
\hline & $\mathrm{BI} 3$ & 0,872 & 0,1848 & Valid & & \\
\hline & $\mathrm{Bl} 4$ & 0,772 & 0,1848 & Valid & & \\
\hline \multirow{4}{*}{$\begin{array}{c}\text { Brand Loyalty } \\
\text { (X4) }\end{array}$} & $\mathrm{BL} 1$ & 0,887 & 0,1848 & Valid & \multirow{4}{*}{0,879} & \multirow{4}{*}{ Reliabel } \\
\hline & $\mathrm{BL} 2$ & 0,893 & 0,1848 & Valid & & \\
\hline & $\mathrm{BL} 3$ & 0,806 & 0,1848 & Valid & & \\
\hline & $\mathrm{BL} 4$ & 0,841 & 0,1848 & Valid & & \\
\hline
\end{tabular}

Sumber: Hasil pengolahan data dengan menggunakan SPSS 23

Uji normalitas bertujuan untuk menguji apakah dalam model regresi, error yang dihasilkan mempunyai distribusi normal atau tidak (Santoso; 2012:230). Kolmogorov-Smirnov test model regresi memenuh asumsi normalitas jika nilai asymp.sig > Alpha $(0,05)$ (Ghozali, 2018:161). Berikut ini adalah Hasil uji normalitas secara grafis dan non grafis:

Tabel 3 Hasil Uji Normalitas Kolmogorov-Smirnov

\begin{tabular}{ccc}
\hline Asymp. Sig. (2-tailed) & Alpha & Hasil \\
\hline 0,353 & 0,05 & Data residual berdistribusi normal \\
\hline Sumber: Hasil pengolahan data dengan menggunakan SPSS 23
\end{tabular}

Bersasarkan tabel 3 diatas, hasil Kolmogorov-Smirnov test, terlihat bahwa nilai Asymp.Sig (2-tailed) > a $(0,353>0,05)$, yang berarti hasil ini menguatkan hasil sebulumnya bahwa model regresi memenuh asumsi normalitas.

Uji Multikolinieritas bertujuan untuk menguji apakah suatu model regresi ditemukan adanya korelasi atau hubungan antar variable 
bebas (Anderson et al; 2014, 703). Model regresi yang baik adalah jika tidak terjadi korelasi antar variable bebas, sehingga variable-variable bebas tidak Ortogonal. (Variable Ortogonal adalah variable independent yang memiliki nilai korelasi antar sesama variable independent samadengan nol).
Model regresi dikatakan tidak terjadi multikolinieritas adalah jika nilai Tolerance > 0,10 atau ketika nilai VIF $<10$ (Sekaran dan Bougie; 2016, 316). Berikut ini adalah hasil uji multikolinieritas:

Tabel 4 Hasil Uji Multikolinearitas

\begin{tabular}{llll}
\hline Variabel & Tolerance & VIF & Hasil \\
\hline Perceived Quality & 0,909 & 1,100 & Tidak Terjadi Multikolinearitas \\
Brand Awareness & 0,349 & 2,867 & Tidak Terjadi Multikolinearitas \\
Brand Image & 0,350 & 2,853 & Tidak Terjadi Multikolinearitas \\
\hline
\end{tabular}

Sumber: Hasil pengolahan data dengan menggunakan SPSS 23

Berdasarkan tabel 3 diatas keseluruhan nilai Tolerance $>0,10$ dan nilai VIF $<10$, sehingga dapat disimpulkan bahwa tidak terjadi multikolinearitas dalam model regresi.

Uji Heteroskedastisitas bertujuan untuk menguji apakah dalam model regresi terdapat ketidaksamaan varians dari residual suatu pengamatan ke pengamatan yang lain. Jika varians dari residual suatu pengamatan ke pengamatan lain tetap, maka disebut Homodekastisitas dan jika berbeda disebut Heteroskedastisitas (Ghozali 2018, 137). Model regresi yang baik adalah jika tidak terjadi heteroskedastisitas, dengan kata lain Model regresi yang baik adalah yang memiliki variance residualnya tetap dari satu pengamatan kepengamatan lainnya atau yang Homoskedastisitas (Ghozali 2018, 137). Untuk menguji Heteroskedastisitas menggunakan metode non-grafik (Uji Glejser) sebuah model regresi ditakakan tidak terjadi Heteroskedastisitas adalah apabila nilai sig $>a$ $(0,05)$ (Ghozali 2018,142). Berikut ini adalah hasil Uji Heteroskedastisitas:

Tabel 5.Hasil Uji Heteroskedastisitas Glejser

\begin{tabular}{llrrrrr}
\hline & & \multicolumn{3}{c}{ Coefficients $^{\mathbf{a}}$} & & \\
\cline { 2 - 7 } & & \multicolumn{2}{c}{$\begin{array}{l}\text { Unstandardized } \\
\text { Coefficients }\end{array}$} & $\begin{array}{c}\text { Standardized } \\
\text { Coefficients }\end{array}$ & \\
\cline { 2 - 7 } Model & \multicolumn{2}{c}{ B } & Std. Error & Beta & \multicolumn{1}{c}{. } & Sig \\
\hline 1 & (Constant) & 2.449 & .649 & & 3.775 & .000 \\
& Perceived_Quality & -.012 & .052 & -.023 & -.239 & .812 \\
& Brand_Awareness & .024 & .056 & .066 & .421 & .675 \\
& Brand_Image & -.110 & .056 & -.308 & -1.973 & .051 \\
\hline
\end{tabular}

a. Dependent Variable: ARES_1

Sumber: Hasil pengolahan data dengan menggunakan SPSS 23

Bersasarkan tabel 5 diatas, dengan mengunakan metode non-grafik (Uji Glejser), terlihat bahwa keseluruhan nilai Sig $>$ a $(0,05)$, yang berarti hasil ini menguatkan hasil sebulumnya bahwa tidak terjadi Heteroskedastisitas model regresi.

Uji autokorelasi bertujuan untuk mengetahui apakah terdapat korelasi antara 
kesalahan pada periode $t$ dengan kesalahan pengganggu pada periode sebelumnya (t-1) dalam suatu model regresi (Anderson et al; 2014,788). Model regresi yang baik ialah model regresi tanpa autokorelasi (Ghozali 2018, 110). Dalam penelitian ini, untuk mendeteksi ada atau tidaknya autokorelasi adalah dengan menggunakan Uji Durbin-Watson (DW test). Dalam Durbin Watson test sebuah model regresi ditakakan tidak terjadi autokorelasi adalah apabila nilai Durbin Watson (DW) terletak diantara nilai du (upper bound) dan 4-du. Berikut ini adalah hasil Uji autokorelasi:

Tabel 6 Hasil Uji Autokorelasi

\begin{tabular}{cc}
\hline Model & Durbin Watson \\
\hline 1 & 2,187
\end{tabular}

Sumber: Hasil pengolahan data dengan menggunakan SPSS 23

Berdasarkan hasil uji Durbin Watson pada tabel 5 diatas, terlihat bahwa nilai Durbin Watson (DW) adalah sebesar 2,187. Nilai DW ini akan dibandingkan dengan nilai du (upper bound) dan 4-du yang diperoleh dari tabel durbin watson. Berdararkan tabel durbin watson dengan jumlah sampel sebanyak 113 dan jumlah variabel independen sebanyak 3 serta nilai signifikasi 0,05 , didapatkan nilai du sebesar 1,736, sehingga nilai 4-du sebesar 2,264. Dari hasil ini telihat bahwa nilai DW terletak diantara nilai du dan 4-du $(1,736<2,187<2,264)$, sehingga dapat disimpulkan bahwa tidak terjadi autokorelasi dalam model regresi.
Uji koefisien korelasi dilakukan untuk mengukur seberapa kuat hubungan natara variabel independen $(X)$ dengan variabel dependen $(Y)$ (Hair et al; 2014:152). Hasil koefisien korelasi terletak antara nilai korelasi 0 yang menunjukkan tidak adanya hubungan antar variabel sampai dengan 1 yang menunjukkan adanya hubungan yang sempurna (Neolaka; 2016,129). Sedangkan uji Koefisien determinasi bertujuan untuk mengetahui besarnya rata-rata variasi variabel dependen yang dapat dijelaskan oleh variabel independen (Hair et al; 2014,152). Berikut ini adalah hasil hasil uji Koefisien Korelasi dan Determinasi:

Tabel 7 Hasil Koefisien Korelasi dan Determinasi

\begin{tabular}{ccccc}
\hline \multicolumn{5}{c}{ Model Summary } \\
\hline Model & $R$ & $R$ Square & Adjusted $R$ Square & $\begin{array}{c}\text { Std. Error of the } \\
\text { Estimate }\end{array}$ \\
\hline 1 & $.827^{\mathrm{a}}$ & .684 & .675 & 1.286 \\
\hline
\end{tabular}

Sumber: Hasil pengolahan data dengan menggunakan SPSS 23

Kuat atau lemahnya korelasi antara variabel independent terhadap variabel dependent ditenutkan dengan melihat nilai $\mathrm{R}$. Pada tabel 7 diatas, terlihat bahwa besarnya niali $R$ adalah 0,827 yang berarti variabel Independen yaitu Perceived Quality (X1), Brand
Awareness (X2), dan Brand Image (X3), memiliki hubungan yang sangat kuat dengan variabel Dependen yaitu Brand Loyalty (Y) karena terletak diantara 0,80-0,999 (Neolaka; 2016,129). Sedangkan untuk mengetahui besarnya rata-rata variasi variabel dependen 
yang dapat dijelaskan oleh variabel independen dapat dilihat dengan menggunakan nilai Adjusted $R$ Square. Pada tabel 7 diatas, nilai Adjusted $R$ Square sebesar 0,675 yang berarti sebesar $67,5 \%$ variasi variabel Brand Equity (Y) dapat dijelaskan oleh variasi variabel Perceived Quality (X1), Brand Awareness (X2), dan Brand Image (X3) sedangkan sisanya $33,0 \%$ dijelaskan oleh variasi variabel lain yang tidak terdapat pada penelitian ini.
Analisis regresi linear berganda digunakan untuk meguji relasi dua atau lebih variabel independen terhadap satu variabel dependen (Anderson et al; 2014:684). Analisa regresi linear berganda akan menghitung besarnya perubahan nilai varibel dependent akibat dari perubahan nilai varibael indepenpent.

Tabel 8 Hasil Analisis Regresi Berganda

\begin{tabular}{|c|c|c|c|c|c|c|}
\hline \multicolumn{7}{|c|}{ Coefficients $^{a}$} \\
\hline \multirow[b]{2}{*}{ Model } & & \multicolumn{2}{|c|}{$\begin{array}{l}\text { Unstandardized } \\
\text { Coefficients }\end{array}$} & \multirow{2}{*}{$\begin{array}{c}\begin{array}{c}\text { Standardized } \\
\text { Coefficients }\end{array} \\
\text { Beta } \\
\end{array}$} & \multirow[b]{2}{*}{$t$} & \multirow[b]{2}{*}{ Sig. } \\
\hline & & $B$ & Std. Error & & & \\
\hline \multirow[t]{4}{*}{1} & (Constant) & 1.547 & 1.051 & & 1.471 & .144 \\
\hline & Perceived_Quality & 219 & .084 & .148 & 2.615 & .010 \\
\hline & Brand_Awareness & .399 & .091 & .401 & 4.394 & .000 \\
\hline & Brand_Image & .407 & .090 & .410 & 4.510 & .000 \\
\hline
\end{tabular}

a. Dependent Variable: Brand_Loyalty

Sumber: Hasil pengolahan data dengan menggunakan SPSS 23

Pengujian hipotesis bertujuan untuk menjawab dugaan yang sudah rumusan dalam Hipotesis null $\left(H_{0}\right)$ dan Hipotesis alternative $\left(H_{a}\right)$, sehigga dapat diambil keputusan, apakah keputusan tersebut menolak atau tidak dapat menolak dugaan dalam hipotesis null $\left(H_{0}\right)$. Pengujian hipotesis dalam penelitian ini untuk mengetahui pengaruh variabel independen terhadap variabel dependen secara individual sehingga pengujiannya dilakukan dengan uji t/ttest. Dalam usaha untuk menolak $\mathrm{H}_{0}$ dalam penelitian ini menggunakan $p$-value dan Critical value Approach. Dengan mengunakan jumlah sampel sebanyak $113(d f=109), 3$ indevendent variabel, level of signifikan $5 \%(a=0,05)$, serta bentuk hipotesis two-tailed diperoleh nilai tabel sebesar 1,960. Berikut ini adalah hasil t-test secara parsial:

Tabel 9 Hasil t-test Parsial

\begin{tabular}{|c|c|c|c|c|c|c|}
\hline \multicolumn{7}{|c|}{ Coefficients $^{a}$} \\
\hline \multirow[b]{2}{*}{ Model } & & \multicolumn{2}{|c|}{$\begin{array}{l}\text { Unstandardized } \\
\text { Coefficients }\end{array}$} & \multirow{2}{*}{$\begin{array}{c}\begin{array}{c}\text { Standardized } \\
\text { Coefficients }\end{array} \\
\text { Beta }\end{array}$} & \multirow[b]{2}{*}{$\mathrm{t}$} & \multirow{2}{*}{ Sig. } \\
\hline & & $B$ & Std. Error & & & \\
\hline \multirow{4}{*}{1} & (Constant) & 1.547 & 1.051 & & 1.471 & .144 \\
\hline & Perceived_Quality & .219 & .084 & 148 & 2.615 & .010 \\
\hline & Brand_Awareness & .399 & .091 & .401 & 4.394 & .000 \\
\hline & Brand_Image & .407 & .090 & .410 & 4.510 & .000 \\
\hline
\end{tabular}

a. Dependent Variable: Brand_Loyalty

Sumber: Hasil pengolahan data dengan menggunakan SPSS 23 
Dengan nilai a sebesar 0,05 , nilai $t_{\text {tabel }}$ sebesar 1,960 serta nilai thitung dan nilai Sig ( $p$ value) pada tabel 9 diatas, Kriteria penolakan $\mathrm{H}_{0}$ dalam pendekatan $p$-value adalah jika nilai $p$ value atau nilai $\mathrm{Sig} \leq \mathrm{a}$, sedangkan dalam penekatan Critical value $\mathrm{H}_{0}$ di tolak jika nilai thitung $\leq-\mathrm{t}_{\text {tabel }}\left(\mathrm{t}_{\mathrm{a} / 2}\right)$ atau jika thitung $\geq \mathrm{t}_{\text {tabel }}\left(\mathrm{t}_{\mathrm{a} / 2}\right)$ (Anderson et al; 2014,702). Berdasarkan tabel 9 diatas, nilai $p$-value atau $\operatorname{Sig} X_{1}$ sebesar 0,010 sedangkan a sebesar 0,05 , maka nilai $p$-value $(0,010)<a(0,05)$. Pada tabel 9 juga telihat bahwa nilai thitung sebesar 2,615 sedangkan tabel sebesar 1,960 , ini berarti nilai thitung $>t_{\text {tabel }}(2,615$ $>1,960)$. Berdasarkan dua pendekatan tersebut dapat disimpulkan bahwa $\mathrm{H}_{0}$ ditolak dan $\mathrm{H}_{a}$ dierima, artinya terdapat pengaruh Perceived Quality terhadap Brand Loyalty.

Berdasarkan tabel 9 diatas, nilai $p$-value atau Sig $X_{2}$ sebesar 0,000 sedangkan a sebesar 0,05 , maka nilai $p$-value $(0,000)<\alpha(0,05)$. Pada tabel tersebut juga telihat bahwa nilai thitung sebesar 4,394 sedangkan tabel sebesar 1,960, ini berarti nilai thitung $>$ tabel $(4,394>1,960)$. Berdasarkan dua pendekatan tersebut dapat disimpulkan bahwa $\mathrm{H}_{0}$ ditolak dan $\mathrm{H}_{\mathrm{a}}$ dierima, artinya terdapat pengaruh Brand Awareness terhadap Brand Loyalty.

Berdasarkan tabel 8 diatas, nilai $p$-value atau $\operatorname{Sig} X_{3}$ sebesar 0,000 sedangkan a sebesar 0,05 , maka nilai $p$-value $(0,000)<a(0,05)$. Pada tabel tersebut juga telihat bahwa nilai thitung sebesar 4,510 sedangkan tabel sebesar 1,960, ini berarti nilai thitung $>$ tabel $(4,510>1,960)$. Berdasarkan dua pendekatan tersebut dapat disimpulkan bahwa $\mathrm{H}_{0}$ ditolak dan $\mathrm{H}_{a}$ dierima, artinya terdapat pengaruh Brand Image terhadap Brand Loyalty.

\section{PENUTUP}

Perceived Quality berpengaruh positif dan signifikan terhadap Brand Loyalty pada Bank Muamalat di DKI Jakarta. Sehingga menjadi penting bagi perbankan syariah terutama Bank Muamalat untuk terus dapat meningkatkan Perceived Quality dari para nasabahnya, karena semakin baik Perceived Quality dari para nasabah kepada perusahaan atau brand maka akan menciptkan dan meningkatkan Brand Loyalty para nasabah kepada perusahaan atau brand tersebut.

Brand Awareness berpengaruh positif dan signifikan terhadap Brand Loyalty pada Bank Muamalat di DKI Jakarta, sehingga pelu bagi perbankan syariah khususnya Bank Muamalat, untuk terus dapat menigkatkat Brand Awareness nasabah terhadap produk atau merek perusahaan, karena semakin baik konsumen mengenal atau sadar akan produk atau merek perusahaan, akan semakin meningatkan Brand Loyalty para nasabahnya.

Brand Image berpengaruh positif dan signifikan terhadap Brand Loyalty pada Bank Muamalat di DKI Jakarta, artinya Brand Image merupakan hal yang penting yang harus perbankan syariah khususnya Bank Muamalat tanamkan dibenak atau pikiran nasabahnya, karena semakin kuat brand image dalam benak atau pikiran konsumen maka akan membentuk dan meningkatkan Brand Loyalty konsumen atau nasabah akan produk atau brand yang bersangkutan. 


\section{REFERENCES:}

Altaf et al. 2017. "Managing the consumer-based brand equity through brand experience in Islamic Banking", Journal of Islamic Marketing, vol. 8 Issue: 2, pp.218-242

Anderson, David R., Dennis J. Sweeny., \& Thomas A. Williams. 2014. Statistics for Business and Economics. $12 e$. USA: Cengage learning.

Ghozali, Imam. 2018. Aplikasi Analisis Multivariate Dengan Program IBM SPSS 25 Edisi 9. Semarang: Badan Penerbit Universitas Diponogoro.

Gounaris, S. dan Stathakopoulos, V. 2004. Antecedents and Consequences of Brand Loyalty: An Empirical Study. Journal of Brand Management, 11 (April), 283-306

Hair, Joseph F., et al. 2014. Multivariate Data Analysis. England: Pearson Education Limited.

Keegan, Warren J. and Mark c. Green. 2015. Global Marketing. Global Education Limited.

Keller, K.L. (1993), "Conceptualizing, measuring, and managing customer-based brand equity", The Journal of Marketing, Vol. 57 No. 1, pp. 1-22.

Keller, K.L. and Lehmann, D.R. (2006), "Brands and branding: research findings and future priorities", Marketing Science, Vol. 25 No. 6, pp. 740-759.

Moisescu, O.I. (2009), "The importance of brand awareness in consumers'buying decision and perceived risk assessment", Management \& Marketing-Craiova, Vol. 7 No. 1, pp. 103-110.

Neolaka, Amos. 2016. Metode Penelitian dan Statistik. Bandung: PT Remaja Rosdakarya.

Otoritas Jasa Keuangan, "Perbankan Syariah and Kelembagaannya". https://www.ojk.go.id/id/kanal/syariah/tentang-syariah/Pages/Perbankan-Syariah.aspx (Diakses September 2018)

Otoritas Jasa Keuangan. "Statistik Perbankan Syariah". https://www.ojk.go.id/id/kanal/syariah/data-danstatistik/statistik-perbankan-syariah/Default.aspx. (Diakses pada September 2018).

Otoritas Jasa Keuangan. "Roadmap Perbankan Syariah". https://www.ojk.go.id/id/kanal/syariah/berita-dankegiatan/publikasi/Pages/Roadmap-Perbankan-Syariah-Indonesia-2015-2019.aspx. (Diakses pada September 2018)

Santoso, S. 2012. Aplikasi SPSS pada Statistik Parametrik. PT Elex Media Komputindo, Jakarta.

Schiffman, Leon $G$ dan Joseph L. Wisenblit. 2015. Consumer Behavior 11 $1^{\text {th }}$. America States: Pearson education.

Sekaran, Uma dan Roger Bougie. 2016. Research Methods for Business. United Kingdom: John Wiley \& Sons Ltd.

Top Brand Award, "Top Brand Index 2018 Fase 1 Kategori: Banking and Finance". https://www.topbrandaward.com/en/top-brand-index-int/ (Diakses September 2018)

Zeithaml, V.A. (1988), "Consumer perceptions of price, quality, and value: a means-end model and synthesis of evidence", The Journal of Marketing, Vol. 52, pp. 2-22. 
